\title{
Research of noise-proof feature of addressable fire indication system with sequential addressing
}

\author{
Ivan Balabanov *, Daria Shtonda and Maria Nikitina \\ Peter the Great St. Petersburg Polytechnic University, Higher School of Technosphere Safety, Fire Safety Department, 29 \\ Politekhnicheskaya st., St.Petersburg, 195251, Russia
}

\begin{abstract}
Currently, one of the ways to quickly detect fires in buildings is an automatic fire alarm system. The alarm loop is the most "vulnerable" part of the security and fire alarm system. This article is devoted to the study of the stability of the address fire alarm system with serial addressing under the influence of electromagnetic interference and other interfering factors. During the study, the system performance was evaluated when changing the parameters of the communication line and the stability of the transmission of the measured controlled parameter from the multicriteria detector having a heat and smoke sensor to the control panel of the DEMP DT №1. The influence of electrical impulse noise on the stability of the system was evaluated.
\end{abstract}

\section{Introduction}

Failure to comply with fire safety requirements often leads to serious consequences, such as property damage, loss of life. Based on the report provided by the Federal state University VNIIPO EMERCOM of Russia the number of fires that occurred from January to September 2017 is 94911 cases [1]. To reduce the damage caused by the fire during evacuation, safety must be ensured. Automatic fire alarm system is an important fire protection measure [2]. One of the most popular types of fire alarm systems is non-address fire alarm system with radial loops, and address with a loop type. Violation of the fire alarm loop due to breakage or short circuit and noise immunity is a problem at the facilities. Short circuits are rare, but their consequences are serious. Previously, the storm was the cause of interference, now $80 \%$ of equipment failure is due to fluorescent lamps, power surges, etc. $[3,4]$. For proper operation, the system must be noise-resistant. The most common types of fire alarm systems are non-address fire alarm system [5], which has a radial loop, and the address fire alarm system, which has a loop type. The address system is expensive. Therefore, it makes sense to use a signal line with serial addressing with the transmission of information by analog, which helps to facilitate the operation of the entire system, is more "survivable" in case of breakage or short circuit [6]. Such situations may result in the disconnection of part of the system or all fire detectors. The ring type of plumes, in the event of such situations, with the help of a receiving-control device, interrogates the line from two sides. In nonaddress loops most of the system "dies" at short circuit [7]. Products that make up the cable line, such as: cable ducts, mounting boxes, fire-resistant cables [8,9], must maintain their performance in case of fire for a period of time [10]. The address system is more expensive, it is recommended to use a signal line with serial addressing with the transmission of information by analog, which will simplify the operation of the entire system, will preserve the capacity at breakage or one short circuit [11].

\section{Methods}

Tests of the address fire alarm system with sequential addressing were carried out using the following equipment:

- bench control and control panel DEMP DT №1;

- flexible fire-resistant cable "Salamander" Kgosng(A)-FRLS 4x075 mm² $230 \mathrm{~m}$;

- three dual-purpose multicriteria fire detectors with built-in short-circuit isolator numbered 2_03, 2_08 and 3_04;

- laboratory power supply HY5003;

- oscilloscope digital storage AKIP-4122/2;

- $0.12 \mathrm{~dB}$ test object;

- metallized polypropylene film capacitor CBB21 mpp 224j 400v;

- 51 Ohm metal film resistor MF-25 (C2-23) 0.25 $\mathrm{W}$;

- the ceramic resistor 120 Ohm YAGEO 5W 1646.

- device for electrical impulse noise;

- pyrometer GM320;

On the right side of the "DEMP" stand, a ring communication line(loop) was connected, which included three dual-purpose fire detectors for measuring the smoke level and temperature with short-circuit isolators (multi-criteria fire detectors). The block

\footnotetext{
* Corresponding author: bid_home@mail.ru
} 
diagram of connection of the fire alarm loop is shown in figure 1 .

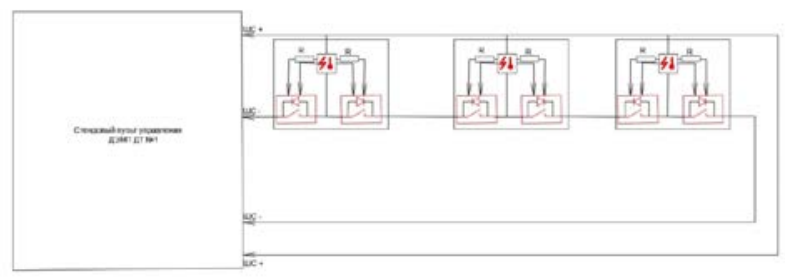

Fig. 1. Block diagram of the connection of the ribbon cable PS.

The smoke sensor of the multicriteria detector was checked to verify the operability of the entire system[12]. For rapid detection of the fire source, the smoke detector must be highly sensitive, as the temperature increases the toxicity of the flue gases[13]. The sensitivity of the smoke detector should be between 0.05 and $0.20 \mathrm{~dB} / \mathrm{m}-1$. A test was conducted sensitivity multicriteriale sensors with the help of the stand "Smoke channel" [14].

The next step was to study the preservation of the system in case of short circuit and disconnection of the communication line.To check the system's operability; we simulated a short circuit and a loop break. For a short circuit in a multicriteria sensor, a small wire was used, which connected two points of the electrical circuit with different potentials on the third multicriteria detector[15].

Next, the Study of the effect of electrical impulse noise. To the loop of the address fire alarm system gradually connected a capacitor of 0.22 UF and a resistance of $50 \mathrm{Ohms}$, and then another insulation resistance of 7.5 ohms and 120 Ohms. In the beginning, the capacitor was connected to the beginning of the loop to the resistance, and then after the resistance. With the help of the control panel, we observed how the long line affects the stability of the work. Wiring diagram shows the capacitor and resistance in figure 2.

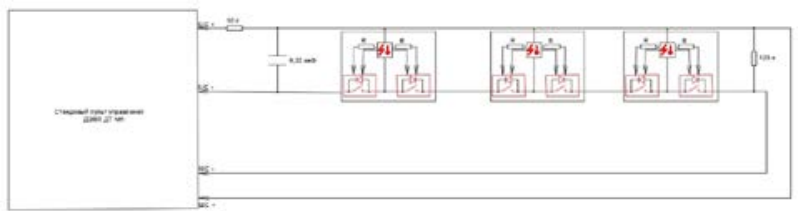

Fig. 2. Scheme of connection of the capacitor and resistance wire.

The fire alarm loop is wrapped with a long wire twice from the device for electrical pulse interference.
When the device for electric pulse interference was turned on, the oscilloscope was used to record how the interference affects the fire alarm loop in the "fire"mode. The fire was simulated in the second detector. The essence of the product of electrical pulse interference is that the relay is initially closed, a current passes through it, the relay is attracted, therefore, the contact is opened, the current disappears and it returns. But at the moment of opening, a spark of the medium-wave range is formed. This spark is a wide-range powerful enough interference and simple device.

\section{Results}

Figure 3 shows a diagram of the results of studies in the installation "Smoke channel" according to GOST R 53325-2012, which shows the results of measurements of the optical density of smoke from the test site (smoldering wick) for a time of 631 seconds.

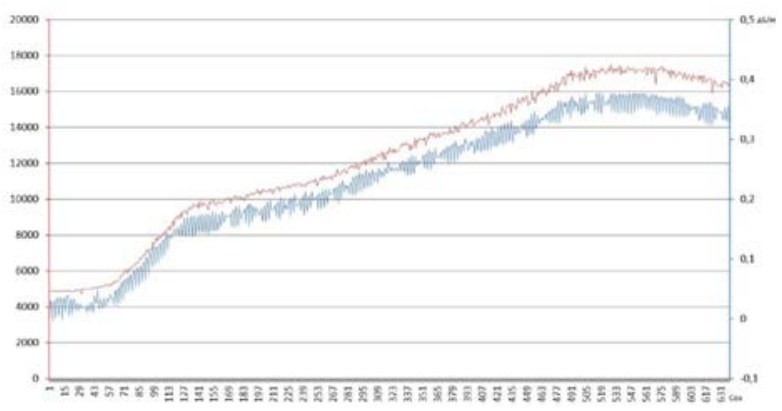

Fig. 3. Measurement Results of optical density of smoke from the test site.

Blue color denotes the values obtained using a laser measuring system for the OPS-2 (measuring the optical density of the smoke, model 2) - laser for measuring the sensitivity of smoke detectors.

The red color indicates the readings of the experimental sample of the smoke detector with a builtin short-circuit insulator transmitted through the DEMP line and reflected on the indicators of the simulator of the receiving and control device in conventional units up to 20000 .

Table 1 shows the measurements of a smoke fire detector in three different parameters: measuring the transparency of the environment, indications of the stand and the length of the interval I.

The analysis of indicators shows in the diagram almost their complete coincidence, from which it can be concluded that the method of transmission of

Table 1. Results of smoke smoke fire detector flue

\begin{tabular}{|c|c|c|}
\hline $\begin{array}{c}\text { The measurement of transparency } \\
\text { of the environment dB }\end{array}$ & $\begin{array}{c}\text { The testimony of the stand, } \\
\text { conventional units }\end{array}$ & Interval I, millisecond \\
\hline Communication current & 60 & $3.9-1.6=2.3$ \\
\hline 0.01 & 180 & $6.8-1.6=5.2$ \\
\hline 0.12 & 300 & $10.3-1.6=8.7$ \\
\hline 0.2 & 400 & $13.2-1.6=11.6$ \\
\hline 0.4 & 800 & $21.4-1.6=19.8$ \\
\hline
\end{tabular}


information on the ring communication line DEMP (relay) has good stability and does not distort. According to the results of Smoking, such values will be programmed in the detectors themselves in the workplace.

The signal line with serial addressing (relay) with information transmission by analog (time-pulse) carries out the transition from interval to interval in a purely logical way without the transmission of the power front. Thus, after switching on the power supply to the power line, the sensors work in turn, one after the other until the last sensor having a maximum address will transmit 2 intervals: odd smoke interval, even-temperature. Single address transfer rate $10 \mathrm{MS}$. processing in the control panel, respectively, is performed by two programs with two arrays of data storage.

Two-wire signal lines of the DEMP type form a current response signal of 1.6 MS at the beginning of the address period, and not at the end. The results of testing the sensitivity of information transmission from the smoke sensor and temperature sensor showed that the multicriteral detector has good stability and high sensitivity, reducing false positives. In standby mode on multicriteria detectors communication indicator glows green when receiving commands from the remote control "DEMP" on multicriterial fire detector indicator when color changes to red. Also in using the feed control in the first interval, you can send a code parcel in the form of an 8-bit code, which protects information about the type of device, its performance, as well as a unique number. In the future, it will be possible to add fire signs, hand detectors and so on to this system.

When checking the performance of the address system with serial addressing, it was found that the work is working properly. In the initial tests faced with the problem of transmitting a current signal with interference, after the improvement of the signal detector in the control panel and control stand DEMP this problem was solved.

In the event of a short circuit or breakage in the fire alarm loop during the line survey, the control panel can turn off the line and conduct a re-survey. The re-poll takes place before the place of the loop violation, after the console begins to poll the line in reverse order from the last address to the place of a short circuit or break.

When polling the plume in reverse order intervals of smoke and temperature do not change places: always first the smoke, then the temperature. When you connect a resistance of 50 Ohms, insulation resistance of 120 Ohms and a capacitor of 0.22 UF, the results showed that when used at large distances, the plume of the fire alarm system will work stably and will not distort

\section{Results and discussion}

Automatic fire alarm systems are important fire protection measures that detect fires in a timely manner and evacuate people to a safe area [16]. Analysis of the regulatory framework shows that the most common technical solution that provides protection for most objects are receiving control devices of fire automation in the loops which include smoke detectors. With high sensitivity, the fire detector is able to generate a signal at the stage of the hearth decay, when the combustion products do not pose a real danger to people. At thermal influence on a loop of the fire alarm system there can be a short circuit or break of a loop, having resulted in not working condition all loop, more than a half or less than a half of a loop. To improve efficiency, plumes of fire alarm system, it is proposed to move the radial loop on the ring via the signal line sequential addressing (relay) the communication of information from analog (temporarily pulsed) by. Which simplifies the operation of the system and has $100 \%$ survivability in one short circuit or breakage? In the development of this system will transmit not only numbers, but also a special code "letters", as it is set to 8-bit encoding. When removing the sensor, the control panel will know which one will be missing. The address system of the fire alarm system with consecutive addressing by results of check of operability of system at in the conditions of influence of the interfering factors possesses good stability and does not introduce distortions. According to the results obtained in determining the sensitivity of multicriteria fire detectors and the accuracy of the transmission values of the controlled parameter on the alarm loop, it can be concluded that the sensitivity of the sensors correspond to GOST R 53325-2012 "fire Technique. Technical means of fire automatics. General technical requirements and test methods" with the ability to use in multimedialnych fire detectors with smoke channels and a temperature sensor, there will be fewer false positives. Installation of such a system will not require special knowledge of programming, which suggests a good prospect of replacing all threshold fire alarm systems for this type of system with sequential addressing.

\section{References}

1. Information on fires and their consequences for January-September 2017 Ministry of the Russian Federation for civil defense, emergency situations and natural disaster response // [Electronic resource]. - - Access mode: http://www.mchs.gov.ru/activities/stats/Pozhari/201 7_god

2. A. A. Novitsky, P. V. Baburov, V. V. Ivanov, V. I. Fomin, A. V. Fedorov, A. A. Nowacki Production and fire automation. Part 1 Production automation for the prevention of fires and explosions. Fire alarm systems, 335 (Academy of state fire service of EMERCOM of Russia, 2005)

3. A. A. Cizek, V. E. Polyakov, D. L. ESIPOVICH, M. N. Lyshevski. Error-correcting fire alarm system on the basis of the laser fibre-optical smoke detector.

4. S. B. Makarov Stability of fire alarm systems to electromagnetic interference

5. A. Vasilyev, D. Tarkhov, I. Bolgov, (...), A. Petrov, V. Filkin Multilayer neural network models based on experimental data for processes of sample deformation and destruction (CEUR Workshop Proceedings, 2016) 
6. A. E. Revenko, K. E. Revenko, N. V. Dem'yanenko Studying techniques of alarm loop monitoring and obstacles affecting its normal functioning. Development of a demonstration stand "studying of alarm loop" for training specialists and teaching students. 1168-1170 (Prospects of development of fundamental Sciences. Proceedings of the XII International conference of students and young scientists(2015)

7. V. V. Sokolyansky Loop fire alarm. Two-wire or four-wire?.- №4(16) - 131-135 (GOU VPO "Academy of civil protection" of the Ministry DND(2018)

8. M. A. Nikitina, A. A. Ponomarev, I. N. Butko, About the directions of researches of fire resistance of cable lines for power supply of devices of fire automation, 186-191 (Collection of scientific papers of the all-Russian scientific-practical conference "Safety in emergency situations"(2018)

9. A. A. Ponomarev, M Nikitina.A., And Butko.N., Development of the furnace for testing the fire resistance of the cable line Scientific and technical journal: Technical and technological problems of service №4 (42), 6-9 (2017)

10. Federal law No. 123 "Technical regulations on fire safety requirements".

11. Magazine "security Technologies" №6, 2010 ADDRESS SYSTEM OPS. THE ADVANTAGES AND DISADVANTAGES.

12. Dubov, S., Babikov, I., Vasilyev, M., Tanklevsky, L. Methods of instrument testing of smoke detectors performance (MATEC Web of Conferences, 245, paper № 11005, 2018)

13. Dubov, S., Babikov, I., Vasilyev, M., Tanklevsky, L. Methods of instrument testing of smoke detectors performance (MATEC Web of Conferences, 245, paper № 11005, 2018)

14. GOST R 53325-2012 "Technical means of fire automation. General requirements and test methods»

15. Senkiv, S.V., Savoshinsky, O.P., Arakcheev, A.V., Tanklevsky, L.T. Development of Methods for Instrumental Diagnostics of Control Devices for Fire Alarm Systems (IOP Conference Series: Earth and Environmental Science, 272 (3), paper № 032013, 2019)

16. Senkiv, S.V., Savoshinsky, O.P., Arakcheev, A.V., Tanklevsky, L.T. Development of Methods for Instrumental Diagnostics of Control Devices for Fire Alarm Systems (IOP Conference Series: Earth and Environmental Science, 272 (3), paper № 032013, 2019)

17. Aytasova, A.S., Karpenko, P.A., Solopova, N.A.Development the risk management system of processes in the enterprise, 1357-1360 (Proceedings of the 2019 IEEE Conference of Russian Young Researchers in Electrical and Electronic Engineering, ElConRus 2019, paper № 8657147). 